\title{
Health disorders and safety measures among workers in Tanta Flax and Oil Company, Egypt
}

\author{
Asmaa Ali El-Feky ${ }^{1} \cdot$ Ibrahim Ali Kabbash ${ }^{2}$ (D) $\cdot$ Hussein Hassan Zayet ${ }^{3} \cdot$ Rania Moustafa El-Sallamy $^{1}$
}

Received: 7 August 2020 / Accepted: 9 November 2020 / Published online: 17 November 2020

(C) Springer-Verlag GmbH Germany, part of Springer Nature 2020

\begin{abstract}
Flax industry has an adverse effect on health status of exposed workers especially in developing countries with lack of appropriate safety measures to identify the health hazards, health disorders among workers in flax and oil company, and to assess the applied safety measures in the factory. A cross sectional study was conducted in Tanta Flax and Oil Company in Egypt. The company includes eight factories which are divided into four departments according to the manufacturing end products. The study was conducted from August 2018 to December 2019 on 353 workers out of 400 workers. An interview questionnaire and clinical medical examination were done to assess the health status of exposed workers. Check list from occupational safety and health administration (OSHA) standards was filled by researcher to check safety measures in work place environment. Respiratory manifestations were detected in $65 \%$ of the examined workers in flax manufacturing departments while allergic manifestations were more obvious in formaldehyde factory department. Approximately one quarter of workers complained that personal protective equipment's are not available. Regarding the mask for dust, nearly half (44.5\%) of the workers rarely used them, and only $7.1 \%$ always use them. Byssinosis was obvious among workers in flax manufacturing and particle board manufacturing department with statistically significant differences between the four departments, in which $36.9 \%$ and $24.1 \%$ of workers in these two departments suffered from chest tightness, respectively. The safety measures were inadequate in flax manufacturing departments and to somewhat sufficient in formaldehyde factory department. Most of exposed workers had inadequate health status due to lack of standard safety measures. Therefore, periodic medical examination should be done regularly with investigation of pulmonary functions of exposed workers with application of high level of safety measure standards in the work place environment.
\end{abstract}

Keywords Flax $\cdot$ Respiratory problems $\cdot$ Formaldehyde $\cdot$ Allergic manifestation

\section{Introduction}

Over 60 million workers are employed in textile and clothing industry worldwide. Flax is one of the natural fibers which were cultivated in ancient Egypt (Goyal et al. 2014). Flax

Responsible Editor: Lotfi Aleya

Ibrahim Ali Kabbash

ibrahim.kabbash@med.tanta.edu.eg; iafkabbash@gmail.com

1 Occupational Medicine at Public Health and Community Medicine department, Faculty of Medicine Tanta University, Tanta, Egypt

2 Public Health and Community Medicine, Faculty of Medicine Tanta University, El-Gueish Street, P.O. Box 19, Tanta, Egypt

3 Occupational Medicine at Occupational and Environmental Department, Faculty of Medicine Cairo University, Cairo, Egypt processing in Egypt is concentrated mainly in Menuf (mostly manual) and in Shubra Melles (mostly mechanical); both are located in the Nile Delta region (Dhirhi et al. 2015). Exposure to flax dust (fibers) had been known to cause byssinosis among the exposed workers. Byssinosis was defined as a respiratory disease associated with inhalation of cotton, flax, and hemp (Morgan et al. 1982; Hinson et al. 2014). Byssinosis is characterized clinically by occasional (early) and then frequent (late) chest tightness towards the end of the first day of work after the week end (Monday chest tightness). Schilling et al. (1963) and Smith et al. (1962) reported high prevalence rate of byssinosis among exposed workers in cotton and flax textile industry (Schilling et al. 1963; Smith et al. 1962). The high morbidity and mortality due to chronic bronchitis and emphysema associated with exposure to flax dust has stimulated a number of studies, to determine the prevalence of various respiratory symptoms in different populations (Kobayashi et al. 2004). 
Several industrialized countries worldwide reported a significant decline in the prevalence of flax dust-induced lung diseases due to implementation of several work place safety measures. The prevalence of byssinosis in the UK is decreasing, while studies in the developing countries showed an increasing prevalence. Studies recorded prevalence rate of around $50 \%$ in workers in flax spinning process (Hinson et al. 2016).

Flax dust-induced lung diseases demonstrate a global health problem in developing countries notably in Africa. The prevalence of Byssinosis grade three is Sudan was $42 \%$ while in Ethiobis it was 43\% and 44\% in Benin (Parikh 1992; Khan and Nanchal 2007; Alemu et al. 2010). In Egypt, Noweir and his coworkers showed that workers handling and processing flax are exposed to high concentrations of dust, and byssinosis prevailed in $22.9 \%$ of exposed workers (Noweir et al. 1975).

Chemicals in the textile industry used in dyeing, printing, and finishing activities which contain benzidine, solvents, and fixatives release formaldehyde that can cause cancer of the nose, lung, and blood.

Exposure to formaldehyde is mainly by dermal contact and by inhalation, causing irritant asthma and allergic manifestations (Malik et al. 2010; Chequer et al. 2013; Akarslan and Demiralay 2015).

Occupational Health and Safety (OHS) systems require the participation of factory workers in the implementation and maintenance of procedures and processes. Engineering technology on dust control is very important, and appropriate ventilation system is essential in preventing respiratory problems. Written accessible information regarding OHS standards and the proper use of personal protective clothes is also important (Khan and Malik 2014). Prevention of occupational diseases is the main and first concern in any medical organization. Therefore, the present study will identify the applied safety measures and the potential health problems, especially the respiratory problems among exposed workers.

\section{Aim of work}

The aim of the present study was to identify the health disorders among workers in flax and oil company and to assess the applied safety measures in this factory.

\section{Participants and methods}

Study design, settings and time A cross-sectional study was carried-out in Tanta Flax and Oil Company, Egypt, from November 2019 to March 2020. The company includes eight factories which are divided into four main departments according to the manufactured end products. There are 3 factories (flax fiber, flax yarn, and spinning factory) that produce flax fiber and yarn. There are also 3 factories (particle board factories, wooden products factory, and block board factory) that produce the wood products. There are also 3 other factories: 1-particle board, wooden products, and block board factory that produce the wood products, 2- Linseed oil factory that produces linseed (flaxseed) oil and animal food and 3- Formaldehyde factory that produce resins, which are transferred to the factories of wood products and used as a glue material.

\section{Study population}

All workers in all departments in the eight factories available during the period of the study were our study population. Three hundred fifty-three workers out of 400 workers were the target population who accepted to participate in the study. Number of workers in flax manufacture department were found to be 157 , particle board has 91 workers, flax oil manufacture has 58, and formaldehyde factory has 47 workers. Those who have history of any health problems related to expected outcome before engagement into this factory were excluded from the study. After exclusion of non-respondents as 30cases were excluded as they had a health problem before engagement and 17 refused to participate and application of exclusion criteria, the response rate was $88.25 \%$.

\section{Tools of study and data collection}

Data were collected from all studied workers via the following:

(1) Interview questionnaire during the time of break that was half an hour in the mid work day, and the interview questionnaire took from 15 to $20 \mathrm{~min}$. The questionnaire was adopted from the International Commission on Occupational Health (ICOH) questionnaire (Rantanen et al. 2013). Questionnaire included 4 sections; the first section was questions about sociodemographic characteristics and complete occupational history. The second section was questions on respiratory symptoms (such as cough, sputum (phlegm), chest tightness, wheeze, breathlessness). The third section was about the eye, nasal, and skin manifestation, and the fourth section was about smoking habits for recording a full smoking history. The studied participants were also asked about the availability of personal protective equipment (PPE) and the regularity of wearing them. When the workers wear PPE once or two times in the 6 days of the week, the answer was rarely. If the workers wear them three or four times in the 6 days of the week, the answer was sometimes, but if worker practiced it five or six times in the 6 days of the week, the answer was always.

(2) Complete clinical examination to study participants was done by the researcher.

Definitions: In accordance with the British Medical Research Council, chronic bronchitis was defined and 
diagnosed by cough and/or phlegm on most days for at least 3 months in the year, for not less than two successive years. Occupational asthma was diagnosed if the person had wheeze and dyspnea in relation to exposure to either a known allergen or to a nonspecific agent in work place especially if is apparent after the rest day (British Medical Research Council 1965).

Byssinosis is defined and diagnosed as tightness or constriction of the chest occurring any time during the work shift, on any working day, without being worse especially on the first day of the working week. The diagnosis of byssinosis was based on the Schilling criteria: Grade $0=$ no symptoms of byssinosis; grade $\mathrm{I} / 2=$ occasional chest tightness or difficulty in breathing on the first day of the work shift; grade I = chest tightness or difficulty in breathing on the first day of every work shift; and grade II = chest tightness or difficulty in breathing on the first day and other days of the work shift (Schilling et al. 1963).

(3) Checking applied safety measures in workplace environment by the researcher using the latest edition of the Occupational Safety and Health Inspection Checklist (2016) (Friend and Kohn 2018). The checklist included 18 items and each item consisted of some questions that covered it, each question was answered by "Yes", "No" or "Not applicable." Score system was done for each item; each unit that achieved equal or more than twothirds of total score $(\geq 66.7 \%)$ was considered to have sufficient level safety measures, those achieved from one-third to less than two-thirds $(33.4-<66.7 \%)$ were considered to have somewhat sufficient safety measures, and those achieved less than one-third $(<33.4 \%)$ were considered to have insufficient level of the applied safety measures.

Statistical design Data were presented and statistically analyzed by using SPSS-V21 (statistical package for social version 21). Numerical data were presented as mean and standard deviation (SD) and categorical data were presented as number and percentage. Chi-squared test was used for statistical analysis. The level of significance was adopted at $P<0.05$.

Administrative consideration Communication with health insurance organization was done to get an official letter that was directed to the manager of the Tanta Flax and Oil Company for performing a medical examination to workers. Verbal consent was taken from each worker before examination after explaining the objectives and benefits of his sharing. An approval was taken from the research ethics committee with an approval code 32724 .

Ethical consideration Subjects were informed about the purpose and procedure of the study and benefits of sharing in it.
Ethical considerations of the study were carried out according to that of Declaration of Helsinki (Carlson et al. 2004).

\section{Results}

Table 1 shows the sociodemographic, work-related data, and smoking habits of the studied workers. It revealed that all workers were males with the mean age of $39.97 \pm 11.81$ and ranged from 21 to 59 . Nearly half of studied workers had primary level education $(46.2 \%)$. Work experience ranged from 1 to 34 with the mean of $15.00+11.15$. Only $9.3 \%$ of studied workers had extra work with similar exposures as current job, and $16.1 \%$ had previous job with exposures as current job. Regarding smoking habits, $41.7 \%$ were current smokers and the majority of them $(75.3 \%)$ were cigarette smokers with the mean duration of $11.35 \pm 8.19$.

Table 2 demonstrates the frequency of use of different personal protective equipment among studied workers. It was found that approximately one quarter of workers said that personal protective equipments are not available. Most of workers $(64.3 \%)$ were not supplied by face cover; only $5.6 \%$ of workers rarely used face cover. Less than half $(40.8 \%$, $40.2 \%$ ) of workers said that eye goggles and ear plug, respectively, were not available. Regarding the mask for dust, approximately half $(44.5 \%)$ of the workers rarely used them, and only $7.1 \%$ always use them. About one quarter of workers $(26.1 \%, 28 \%$, and $27.2 \%)$ rarely used eye goggles, gloves, and ear plugs, respectively. Only few percents of the workers $(7.1 \%, 2.8 \%, 5.1 \%$, and $7.4 \%)$ always use different personal protective equipment.

Table 3 illustrates distribution of studied workers in relation to respiratory manifestations. There were statistically significant differences between the four departments regarding cough, wheezing, and chronic bronchitis $(P<.005)$. More than half $(59.2 \%, 58.6 \%)$ of workers in flax manufacturing department complained of cough and wheeze, respectively, and the majority of them $(73.1 \%, 83.6 \%)$ improved when they were off from the work. Less than half (40.8\%) of workers in the flax-producing department had chronic bronchitis, while nearly to one quarter in other departments had chronic bronchitis. Most abnormalities in chest examination were found in flax manufacturing department and particle board department, respectively, as $25.5 \%$ and $16.5 \%$ of the studied workers had barrel-shape chest. Also, 27.4\% and $23.1 \%$ of the studied workers in flax manufacturing department and particle board department, respectively, had rhonchi with statistically significant difference between the four departments. Regarding the respiratory rate, it was higher in flax manufacturing department and particle board department than other departments with a mean of $21.21 \pm 10.35$ and $20.36 \pm 9.21$, respectively, with significant difference between the four departments. Table 4 shows the relationship between byssinosis grades 
Table 1 Sociodemographic, job characteristics, and smoking habits of the studied workers in Tanta Flax and Oil Company
Sociodemographic characteristics

Studied workers $(n=353)$

No. $\%$

\begin{tabular}{llc}
\hline Age/years & & \\
$20-30$ & 94 & $26.6 \%$ \\
$31-40$ & 85 & $24.1 \%$ \\
$41-50$ & 96 & $27.2 \%$ \\
$51-60$ & 79 & $22.3 \%$ \\
Mean \pm SD & $39.97 \pm 11.81$ & \\
Range & $21-59$ & \\
Education & & $28.9 \%$ \\
Illiterate & 102 & $46.2 \%$ \\
Primary & 163 & $15.6 \%$ \\
Secondary & 55 & $9.3 \%$ \\
University & 33 & \\
Duration of work/years & & \\
Mean \pm SD & $15.00 \pm 11.15$ & \\
Range & $1-34$ & $16.1 \%$ \\
Extra work with similar exposures as current job & 33 & \\
Previous job with exposures as current job & 57 & $38.8 \%$ \\
Smoking & & $18.7 \%$ \\
Non-smoker & 137 & $41.7 \%$ \\
Past smoker & 66 & $75.3 \%$ \\
Current smoker & 150 & \\
Cigarette & 113 & \\
Shisha & 37 & \\
Duration of smoking/year & $11.35+8.19$ \\
Mean \pm SD & $1-24$ & \\
Range & & \\
& & \\
& &
\end{tabular}

(chest tightness), sociodemographic data, duration of exposure, and work department. Regarding age and years of exposure, grade $1 / 2$ byssinosis was more among the young aged workers, $11.7 \%$ among those from 20 to 30 years, and $12.9 \%$ from 31 to 40 years. Grade I and II byssinosis were more among older workers with longer duration of exposure; grade I byssinosis was present in $24 \%$ of those aged from 41 to 50 years and in $20.5 \%$ from 51 to 60 years; grade II byssinosis in $2.1 \%$ and $9 \%$ of those aged from 41 to 50 years and 51 to 60 years, respectively, with statistically significant difference in between them. Regarding work department, byssinosis was obvious among workers in flax manufacturing and particle board manufacturing department with statistically significant differences between the four departments, in which $36.9 \%$ and $24.1 \%$ of workers in these two departments suffered from chest tightness, respectively. A total of $26.8 \%$ and $15.4 \%$ of them had grade I byssinosis, and $4.6 \%$ and $3.3 \%$ of them had grade II byssinosis, respectively. A limited
Table 2 Frequency of use of personal protective equipment by the studied workers

\begin{tabular}{|c|c|c|c|c|c|c|c|c|c|c|}
\hline \multirow[t]{2}{*}{ Protective equipment } & \multicolumn{2}{|c|}{ Not available } & \multicolumn{2}{|c|}{ Available not used } & \multicolumn{2}{|c|}{ Rarely } & \multicolumn{2}{|c|}{ Sometimes } & \multicolumn{2}{|c|}{ Always } \\
\hline & No. & $\%$ & No. & $\%$ & No. & $\%$ & No. & $\%$ & No. & $\%$ \\
\hline Masks for dust & 84 & 23.8 & 87 & 24.6 & 157 & 44.5 & 0 & 0.0 & 25 & 7.1 \\
\hline Eye googles & 144 & 40.8 & 83 & 23.5 & 92 & 26.1 & 24 & 6.8 & 10 & 2.8 \\
\hline Gloves & 130 & 36.8 & 70 & 19.8 & 99 & 28.0 & 36 & 10.2 & 18 & 5.1 \\
\hline Head cover & 102 & 28.9 & 88 & 24.9 & 134 & 38.0 & 26 & 7.4 & 3 & 0.8 \\
\hline Protective shoes & 11 & 37.1 & 81 & 22.9 & 115 & 32.6 & 24 & 6.8 & 2 & 0.6 \\
\hline Ear plugs & 142 & 40.2 & 89 & 25.2 & 96 & 27.0 & 0 & 0.0 & 26 & 7.4 \\
\hline Face cover & 227 & 64.3 & 104 & 29.5 & 20 & 5.6 & 2 & 0.6 & 0 & 0.0 \\
\hline
\end{tabular}


Table 3 Respiratory Manifestations of workers in different departments

\begin{tabular}{|c|c|c|c|c|c|c|c|c|c|}
\hline \multirow{3}{*}{ Respiratory Manifestations } & \multicolumn{8}{|c|}{ Studied groups } & \multirow{3}{*}{$X^{2}(P$ value $)$} \\
\hline & \multicolumn{2}{|c|}{$\begin{array}{l}\text { Flax manufacture } \\
(n=157)\end{array}$} & \multicolumn{2}{|c|}{$\begin{array}{l}\text { Particle board } \\
\text { manufacture }(n=91)\end{array}$} & \multicolumn{2}{|c|}{$\begin{array}{l}\text { Flax oil manufacture } \\
(n=58)\end{array}$} & \multicolumn{2}{|c|}{$\begin{array}{l}\text { Formaldehyde factory } \\
(n=47)\end{array}$} & \\
\hline & No. & $\%$ & No. & $\%$ & No. & $\%$ & No. & $\%$ & \\
\hline Chronic bronchitis & 64 & 40.8 & 2 & 27.4 & 13 & 22.4 & 8 & 17.0 & $28.2(0.05 *)$ \\
\hline \multicolumn{10}{|l|}{ Respiratory symptoms } \\
\hline Cough & 93 & 59.2 & 33 & 36.3 & 24 & 41.4 & 18 & 38.3 & \multirow[t]{2}{*}{$15.83(0.01 *)$} \\
\hline Off work improvement & 68 & 73.1 & 27 & 79.4 & 20 & 3.3 & 11 & 61.0 & \\
\hline Sputum & 55 & 35 & 32 & 35.2 & 25 & 43.1 & 20 & 42.6 & \multirow[t]{2}{*}{$1.82(0.59)$} \\
\hline Off work improvement & 47 & 81 & 25 & 78.1 & 22 & 88.0 & 17 & 85 & \\
\hline Wheezing & 92 & 58.6 & 29 & 31.9 & 16 & 27.6 & 13 & 27.3 & \multirow[t]{2}{*}{$30.72(0.001 *)$} \\
\hline Off work improvement & 46 & 83.6 & 19 & 70.4 & 14 & 82.4 & 11 & 73.9 & \\
\hline \multicolumn{10}{|l|}{ Respiratory signs } \\
\hline Barrel chest & 40 & 25.5 & 15 & 16.5 & 6 & 10.6 & 8 & 17.0 & $1.25(0.91)$ \\
\hline Abnormal respiratory movement & 64 & 40.8 & 22 & 24.2 & 18 & 31 & 11 & 25.0 & $8.36(0.03 *)$ \\
\hline Rhonchi & 43 & 27.4 & 21 & 23.1 & 11 & 19.0 & 7 & 14.9 & $5.65(0.25)$ \\
\hline Crepitation & 28 & 17.8 & 12 & 13.2 & 4 & 6.9 & 2 & 4.3 & $7.50(0.04 *)$ \\
\hline Plural rub & 14 & 8.9 & 5 & 5.5 & 3 & 5.2 & 2 & 4.3 & $9.88\left(0.03^{*}\right)$ \\
\hline \multicolumn{10}{|l|}{ Respiratory rate } \\
\hline Mean \pm SD & \multicolumn{2}{|c|}{$21.21 \pm 10.35$} & \multicolumn{2}{|c|}{$20.36 \pm 9.21$} & \multicolumn{2}{|c|}{$18.36 \pm 7.25$} & \multicolumn{2}{|c|}{$17.24 \pm 8.24$} & $F=2.23$ \\
\hline Min-max & \multicolumn{2}{|c|}{$13-27$} & \multicolumn{2}{|c|}{$13-24$} & \multicolumn{2}{|c|}{$14-23$} & \multicolumn{2}{|c|}{$15-22$} & $P=0.03^{*}$ \\
\hline
\end{tabular}

* Statistically significant at $P \leq 0.05$ Bonferroni test for respiratory rate: group of flax manufacture significantly different from both flax oil and formaldehyde groups

percentage of workers $(10.3 \%$ and $13.3 \%$ of $)$ in oil manufacturing and formaldehyde departments, respectively, complained of chest tightness. As regard smoking habit, there were no statistically significant differences detected between them.

Table 5 demonstrates distribution of studied workers in relation to nasal, eye, and skin manifestations. It revealed that there was statistically significant difference between the four departments except from sneezing. Regarding nasal symptoms, $17 \%$ of workers in formaldehyde factory complained of sneezing and nasal bleeding, also the majority of workers in formaldehyde factory complained of eye and skin symptoms compared to other departments with statistically significant difference between the four departments.

Table 6 illustrates the level of safety measures in work place in studied factory departments. It revealed that $37.5 \%$ and $50 \%$ of the buildings were somewhat sufficient regarding the most items of the safety levels in the work place, while only $12.5 \%$ of the buildings were sufficient regarding work place in general, evacuation routes, electrical safety, and health and safety training. As regards fire protection, it was to somewhat sufficient in $37.5 \%$, and sufficient in $50 \%$ of the studied departments.

Table 7 illustrates the significant predictor factors affecting byssinosis. It was found that department of work and the use of personal protective equipment were the significant predictor factors affecting the presence of byssinosis $(P>0.05)$.

\section{Discussion}

Exposure to flax dust increases the prevalence of cough, chest tightness, chronic bronchitis, and dyspnea among exposed workers. Cough and chest tightness in exposed workers occurred not only on Mondays (Oldenburg et al. 2007). Studies detected that chronic exposure to cotton dust and flax dust among textile workers can result in permanent impairment of lung function (Noweir et al. 1990; Mahmoud et al. 2004).

The current study found that there was statistically significant difference between the four departments regarding cough, chronic bronchitis, wheezing, and dyspnea $(P<.005)$. Approximately half of workers in flax manufacturing department complained of cough and wheeze and the majority reported improvement when they were off from the work. A total of $40.8 \%$ of workers in the flax-producing department were diagnosed as having chronic bronchitis. The high prevalence of respiratory problems in this department may be due to high dust concentration in these rooms with no adequate ventilation and only; $7.1 \%$ of workers always wear masks. Also, a study by Ahasan and his colleagues in 
Table 4 Relationship between byssinosis grades and socio demographic data and work department

$$
\text { Byssinosis grade }
$$

\begin{tabular}{|c|c|c|c|c|c|c|c|c|c|}
\hline & & & & & & & & & \\
\hline \multirow[t]{2}{*}{ Sociodemographic data } & \multicolumn{2}{|c|}{ Grade $1 / 2$} & \multicolumn{2}{|c|}{ Grade I } & \multicolumn{2}{|c|}{ Grade II } & \multicolumn{2}{|c|}{ Total byssinosis } & \multirow[t]{2}{*}{$X^{2}(P)$} \\
\hline & No. & $\%$ & No. & $\%$ & No. & $\%$ & No. & $\%$ & \\
\hline \multicolumn{10}{|l|}{ Age (years) } \\
\hline $20-30(n=94)$ & 11 & $11.7 \%$ & 8 & $8.5 \%$ & 0 & $0.0 \%$ & 13 & $20.2 \%$ & \multirow[t]{4}{*}{$43.3(0.001 *)$} \\
\hline $31-40(n=85)$ & 11 & $12.9 \%$ & 11 & $12.9 \%$ & 1 & $1.2 \%$ & 23 & $27.1 \%$ & \\
\hline $41-50(n=96)$ & 2 & $2.1 \%$ & 23 & $24.0 \%$ & 2 & $2.1 \%$ & 27 & $28.1 \%$ & \\
\hline $51-60(n=79)$ & 0 & $0.0 \%$ & 16 & $20.5 \%$ & 7 & $9.0 \%$ & 23 & $29.1 \%$ & \\
\hline \multicolumn{10}{|l|}{ Duration of work (years) } \\
\hline$>10(n=84)$ & 8 & $9.5 \%$ & 0 & $0.0 \%$ & 0 & $0.0 \%$ & 8 & $9.5 \%$ & \multirow[t]{4}{*}{$70.1(0.001 *)$} \\
\hline $10-20(n=92)$ & 14 & $15.2 \%$ & 7 & $7.6 \%$ & 0 & $0.0 \%$ & 21 & $22.8 \%$ & \\
\hline $21-30(n=97)$ & 2 & $2.1 \%$ & 28 & $28.9 \%$ & 2 & $2.1 \%$ & 32 & $32.9 \%$ & \\
\hline$<30(n=80)$ & 0 & $0.0 \%$ & 23 & $28.8 \%$ & 8 & $10 \%$ & 31 & $38.8 \%$ & \\
\hline \multicolumn{10}{|l|}{ Work department } \\
\hline Flax $(n=157)$ & 9 & $5.7 \%$ & 42 & $26.8 \%$ & 7 & $4.6 \%$ & 58 & $36.9 \%$ & \multirow[t]{4}{*}{$25.5(0.001 *)$} \\
\hline Particle board $(n=91)$ & 5 & $5.5 \%$ & 14 & $15.4 \%$ & 3 & $3.3 \%$ & 22 & $24.1 \%$ & \\
\hline Flax oil $(n=58)$ & 6 & $10.3 \%$ & 0 & $0.0 \%$ & 0 & $0.0 \%$ & 6 & $10.3 \%$ & \\
\hline Formaldehyde $(n=47)$ & 4 & $8.5 \%$ & 2 & $4.3 \%$ & 0 & $0.0 \%$ & 6 & $13.3 \%$ & \\
\hline \multicolumn{10}{|l|}{ Smoking } \\
\hline Non-smoker $(n=137)$ & 10 & $7.3 \%$ & 16 & $11.7 \%$ & 4 & $2.9 \%$ & 30 & $21.8 \%$ & \multirow[t]{4}{*}{$6.1(0.19)$} \\
\hline Current smoker $(n=150)$ & 5 & $7.6 \%$ & 12 & $18.2 \%$ & 0 & $0.0 \%$ & 45 & $30.0 \%$ & \\
\hline Past Smoker $(n=66)$ & 9 & $6.0 \%$ & 30 & $20.0 \%$ & 6 & $4.0 \%$ & 17 & $25.7 \%$ & \\
\hline Total $(n=353)$ & 24 & $6.7 \%$ & 58 & $26.4 \%$ & 10 & $2.8 \%$ & 92 & $26.1 \%$ & \\
\hline
\end{tabular}

*Statistically significant at $P \leq 0.05$

Bangladesh found that only $15.7 \%$ of the workers in the textile factories were using masks (Ahasan et al. 2000). Thus, respiratory protective devices (e.g., breathing apparatus, gas mask, dust-proof respirator) should be effectively used to protect against the penetration and deposition of flax dusts. Shephard and Barnhart noted that challenge to reduce lung disorders is by using the appropriate personal protective clothes (Shephard 1961; Barnhart 1997).

The term byssinosis is generally applied to one or more respiratory symptoms associated with the cotton dust, flax, and hemp dust in the workplace. The present study showed that about $36.9 \%$ of workers in flax manufacturing and $24.1 \%$ particle board manufacturing department suffered from chest tightness, $26.8 \%$ and $15.4 \%$ had grade I byssinosis, and $4.6 \%$ and $3.3 \%$ of workers in flax manufacturing and particle board manufacturing department, respectively, had grade II byssinosis. Byssinosis was obvious more in flax manufacturing department especially those in hackling and spinning due to high dust concentration especially with the defect in engineering control measures, and there was no supervision on workers to wear PPE. This study demonstrates higher rate of respiratory symptoms in older workers with more duration of work as they were exposed to high cumulative dose of dust.
This study goes hand in hand with a study by Noweir et al. in Egypt in 1975, where a representative sample of the workers involved in the flax processing was examined and showed that workers of handling and processing flax were exposed to high concentrations of dust. Byssinosis prevailed in $22.9 \%$ of the examined workers, with $5.4 \%$ in grade I and $13.3 \%$ grade II. Hackling combing has long been known to be the most dangerous operation in flax processing (Noweir et al. 1975).

Also, a study by Smith et al. in East Scotland among flax workers found higher prevalence of byssinosis in the flax mills $(22.92 \%)$, and the majority were byssinosis grade I, due to high dust concentration and lack of safety measures (Smith et al. 1962).

In contract to a survey study by Cinkotai et al. in France 1988 , they reported that $20 \%$ of the flax workers suffered from persistent cough, $25 \%$ from chronic phlegm production, and only $12.5 \%$ suffer from byssinosis even though they were heavily exposed to airborne dust and bacteria. The low prevalence of byssinosis might be due to a relatively low concentration of the causative agent despite high airborne contamination (Cinkotai et al. 1988). Also, Singh et al. 2019, reported lower levels of respiratory disorders among dust exposed 
Table 5 Irritant and allergic manifestations among the studied workers

\begin{tabular}{|c|c|c|c|c|c|c|c|c|c|}
\hline \multirow[t]{3}{*}{ Irritant and allergic manifestations } & \multicolumn{8}{|c|}{ Studied groups } & \multirow[t]{3}{*}{$X^{2}(P$ value $)$} \\
\hline & \multicolumn{2}{|c|}{ Flax manufacture $(n=157)$} & \multicolumn{2}{|c|}{$\begin{array}{l}\text { Particle board } \\
\text { manufacture } \\
(n=91)\end{array}$} & \multicolumn{2}{|c|}{$\begin{array}{l}\text { Flax oil } \\
\text { manufacture } \\
(n=58)\end{array}$} & \multicolumn{2}{|c|}{$\begin{array}{l}\text { Formaldehyde } \\
\text { factory } \\
(n=47)\end{array}$} & \\
\hline & No. & $\%$ & No. & $\%$ & No. & $\%$ & No. & $\%$ & \\
\hline \multicolumn{10}{|l|}{ Nasal symptoms } \\
\hline Sneezing & 22 & 14.0 & 15 & 16.5 & 6 & 10.6 & 8 & 17.0 & $1.25(0.91)$ \\
\hline Itchy nose & 25 & 15.9 & 12 & 13.2 & 6 & 10.6 & 18 & 38.3 & $15.3(0.002 *)$ \\
\hline Nasal bleeding & 11 & 7.0 & 4 & 4.4 & 1 & 1.7 & 8 & 17.0 & $9.03(0.03 *)$ \\
\hline \multicolumn{10}{|l|}{ Eye symptoms } \\
\hline Burning eyes & 25 & 15.9 & 21 & 23.1 & 12 & 20.7 & 37 & 78.7 & $10.3\left(0.01^{*}\right)$ \\
\hline Itching eyes & 25 & 15.9 & 15 & 16.5 & 12 & 20.7 & 19 & 40.4 & $12.7(0.05 *)$ \\
\hline \multicolumn{10}{|l|}{ Skin manifestations } \\
\hline Chemical skin burn & 13 & 8.3 & 19 & 20.9 & 11 & 19.0 & 35 & 74.4 & $11.3(0.001 *)$ \\
\hline Contact dermatitis & 22 & 14.0 & 15 & 16.5 & 9 & 15.5 & 24 & 54.5 & $22.0(0.001 *)$ \\
\hline Allergic dermatitis & 5 & $3 . \%$ & 5 & 5.4 & 2 & 3.4 & 20 & 42.6 & $11.3(0.001 *)$ \\
\hline
\end{tabular}

*Statistically significant at $P \leq 0.05$

workers in Eastern Nepal in 2019. Chest tightness was reported among only $5.4 \%$ in textile workers and cough symptoms among only $8.3 \%$ of textile workers. This low prevalence of respiratory disorders may be due to better adherence of workers to safety measures and regular use of personal protective equipment (Singh et al. 2019).

Byssinosis can occur in a few individuals after short exposure to flax dust as 6 months. The prevalence rises from
Table 6 The levels of safety measures for different items in work place in the studied Factory Departments

\begin{tabular}{|c|c|c|c|c|c|c|}
\hline \multirow[t]{3}{*}{ Items } & \multicolumn{6}{|c|}{ Studied work departments $(n=8)$} \\
\hline & \multicolumn{2}{|c|}{ Insufficient } & \multicolumn{2}{|c|}{ Somewhat sufficient } & \multicolumn{2}{|c|}{ Sufficient } \\
\hline & No. & $\%$ & No. & $\%$ & No. & $\%$ \\
\hline Workplace in general & 4 & 50.0 & 3 & 37.5 & 1 & 12.5 \\
\hline Walking and working surfaces & 2 & 25.0 & 4 & 50.0 & 2 & 25.0 \\
\hline Evacuation and exit routes & 3 & 37.0 & 4 & 50.0 & 1 & 12.5 \\
\hline Fire protection and prevention & 1 & 12.5 & 3 & 37.5 & 4 & 50.0 \\
\hline Hazardous materials & 1 & 12.5 & 4 & 50.0 & 3 & 37.5 \\
\hline Personal protective equipment & 3 & 37.5 & 3 & 37.5 & 2 & 25.0 \\
\hline Respiratory protection & 3 & 37.5 & 3 & 37.5 & 2 & 25.0 \\
\hline Ventilation & 2 & 25.0 & 4 & 50.0 & 2 & 25.0 \\
\hline Environmental conditions & 4 & 50.0 & 2 & 25.0 & 2 & 25.0 \\
\hline Noise & 4 & 50.0 & 4 & 50.0 & 0 & 0.0 \\
\hline Hazardous chemical exposure & 5 & 62.5 & 3 & 37.5 & 0 & 0.0 \\
\hline Records & 2 & 25.0 & 6 & 75.0 & 0 & 0.0 \\
\hline First aid requirements & 5 & 62.5 & 3 & 37.5 & 0 & 0.0 \\
\hline Emergency response & 3 & 37.5 & 3 & 37.5 & 2 & 25.0 \\
\hline Control of hazardous emergency & 4 & 50.0 & 4 & 50.0 & 0 & 0.0 \\
\hline Electrical safety work practices & 2 & 25.0 & 5 & 62.5 & 1 & 12.5 \\
\hline Machine guarding & 1 & 12.5 & 4 & 50.0 & 3 & 37.5 \\
\hline Health and safety training & 3 & 37.5 & 4 & 50.0 & 1 & 12.5 \\
\hline
\end{tabular}


Table 7 Logistic regression significant predictor factors affecting byssinosis among the studied workers

\begin{tabular}{lcll}
\hline $\begin{array}{l}\text { Significant predictor } \\
\text { variables }\end{array}$ & $\bullet$ Wald & $\bullet P$ value & $\begin{array}{l}\text { Confidence } \\
\text { interval EXP(B) }\end{array}$ \\
\hline Age & 4.41 & 0.51 & $0.70-1.35$ \\
Years of exposure & 3.001 & 0.36 & $0.71-1.12$ \\
Use of PPE & 2.96 & $0.007^{*}$ & $0.04-0.74$ \\
Smoking & 2.25 & 0.45 & $0.82-1.32$ \\
Department of work & 17.43 & $0.003^{*}$ & $0.42-0.78$ \\
\hline
\end{tabular}

* Statistically significant at $P \leq 0.05$

2 years, reaching a peak at 10 years' dust exposure. The present study showed a significant association between the byssinosis grades and age of workers; grade $1 / 2$ byssinosis was more among the young age, while grade I and II were more in older workers, with longer duration of work. These results are in line with Elwood et al. in Northern Ireland; they found progression in the severity of symptoms with an increase in age, and duration of employment of the affected workers $(P>0.05)$ (Elwood et al. 1965), while Noweir et al. 1975, reported that the prevalence was maximum among the workers who had been exposed for a period ranging from 20 to 30 years $(33.7 \%)$ and was slightly decreased among those exposed for more than 30 years (29.8\%) (Noweir et al. 1975).

Of interest and importance in this context is the relationship of cigarette smoking to byssinosis in flax workers. Our study found that there was no significant association between byssinosis grade and smoking habit. Also, Elwood et al. in Northern Ireland in 1965 showed that there was no significant association between byssinosis grade and smoking habit (Elwood et al. 1965).

Long-term exposure to elevated levels of formaldehyde especially in the occupational exposures causes upper and lower airway irritation, eye irritation, coughing, wheezing, and dermal allergic reactions in occupationally exposed formaldehyde workers (Zhang et al. 2009; McGwin Jr et al. 2010; Kim et al. 2011).

The present study revealed that nasal symptoms were found in $17 \%$ of workers in formaldehyde factory as the majority of workers were not provided by face shield, also the majority of workers in formaldehyde factory complained of eye and skin symptoms with statistically significant difference between the four departments. The inhaled formaldehyde is classified as an irritant-induced asthma, and because of its airway-irritating properties, it may also aggravate preexisting asthma (Kim et al. 2011).

In accordance with this study, Jafari et al. (2015) conducted case-control study at North Wood Factory, northern Iran, and revealed that the prevalence of eye, nasal, and throat irritation symptoms among exposed workers was significantly higher than the prevalence of irritation symptoms in the control group (Jafari et al. 2015).
There are several safety and health issues associated with the textile industry which play an important role in any industry. It is essential that the workers be aware of the various occupational hazards in the industry. At the same time, it is necessary that the manager takes the necessary steps to protect workers from potential hazardous situations (Zhang et al. 2009). The ILO (International Labor Organization) and WHO (World Health Organization) programs on occupational hygiene and checklists were implemented in Southeast Asia, Africa, and Latin America through different projects, which are still lacking in Egypt (Jacobsen et al. 1994; WHO 1986, 1994).

The current study revealed that $37.5 \%$ and $50 \%$ of the studied departments were somewhat sufficient regarding most items of the safety levels in the work place, while only $12.5 \%$ of the buildings were sufficient regarding work place in general, evacuation routes, respiratory protection, environmental conditions, electrical safety, and health and safety training. This is due to the concept of occupational health and safety in developing countries which are restricted and limited resulting in increased incidence of occupational diseases and the damages are high.

This goes hand in hand with a study by Parimalam et al. 2006 in which they conducted a study in 18 garment manufacturing units located in Madurai city (India) among a total of 216 workers. They found that the units lack efficient safety measures, first aid kits, fire extinguishers, and alarms and it was noted in most of the units which put the workers under great risk in emergency. Protective equipment like gloves was not provided to the workers in several units (Parimalam et al. 2006).

Also, Ahasan et al. in Bangladesh conducted a study among textile industry workers and found that air circulation was implemented by exit-fan or blower and opening the windows that was not sufficient for good air flow distribution in the workrooms (Ahasan et al. 2000). Saarinen emphasized the dilution ventilation and one- to three-stage air-conditioning system that can be used to control the dust and to keep the standard dust concentrations under $0.1 \mathrm{mg} / \mathrm{m} 3$ (Saarinen 1997).

\section{Limitations of the study}

The workers were hesitant to cooperate for fear of losing their jobs if health problems are detected in the examination, due to the lack of social and political rights for the workers' union. Also, pulmonary function tests could not be done due to spread of COVID-19 pandemic at time of study and the fear of transmission of infection by factory managers.

\section{Conclusions}

Workers in flax and oil company are exposed to various occupational hazards especially exposure to flax dusts and 
formaldehyde. Workers exposed to flax dust present more respiratory symptoms. The prevalence of byssinosis in the company was $40.4 \%$ especially among old age workers with more years of work exposures. Workers exposed to formaldehyde showed increased prevalence of irritant skin, eye, and nose symptoms. Most of the PPEs were rarely used by workers. The majority of safety measures were in sufficient in the company.

\section{Recommendations}

Personal protective equipment (PPE) should be applied and be available to all workers and its use should be mandatory. Also, all workers using PPE should be trained in their use and maintenance. Periodic medical examination should be done regularly for early detection of any health disorders. Safety measures should be checked periodically for ensuring their utility during emergency situations. Provision of local exhaust ventilation that uses suction, based on the principle of a vacuum cleaner, is to be encouraged in the high dusty sections to remove dust from the air.

Authors' contributions Asmaa Ali El-Feky: data collection, data analysis, and writing the manuscrip. Ibrahim Ali Kabbash: supervise data collection and analysis, revision the manuscript. Hussein Hassan Zayet: supervise data collection and analysis. Rania Mostafa El-Sallamy: sharing in data collection and analysis and writing the manuscript.

Data Availability Original data are available on request form the corresponding author.

\section{Compliance with ethical standards}

Conflict of interest The authors declare that they have no conflicts of interest.

Ethical approval All procedures performed were in accordance with the ethical standards of the institutional and national research committee and with the 1964 Helsinki declaration and its later amendments or comparable ethical standards.

Informed consent Informed consent was obtained from all participants of this study.

Consent to publish On behave of myself and coauthors I consent to transfer this paper to ESPR for publication.

\section{References}

Ahasan MR, Ahmad SA, Khan TP (2000) Occupational exposure and respiratory illness symptoms among textile industry workers in a developing country. Appl Occup Environ Hyg 15(3):313-320

Akarslan F, Demiralay H (2015) Effects of textile materials harmful to human health. Acta Phys Pol A 128(2B):407-409
Alemu K, Kumie A, Davey G (2010) Byssinosis and other respiratory symptoms among factory workers in Akaki textile factory. Ethiop J Health Dev 24(2):133-139

Barnhart S (1997) Dust-Induced Lung Diseases: New and Persistent Challenges. Afr Newsl Occup Health Safety 7:3

British Medical Research Council (1965) Definition and classification of chronic bronchitis for clinical and epidemiological purposes. Lancet $1: 775-779$

Carlson RV, Boyd KM, Webb DJ (2004) The revision of the declaration of Helsinki: past, present and future. Br J Clin Pharmacol 57(6): 695-713

Chequer FD, de Oliveira GA, Ferraz ER, Cardoso JC, Zanoni MB, de Oliveira DP (2013) Textile dyes: dyeing process and environmental impact. Eco-friendly textile dyeing and finishing. Avialabe at: http// www.intechopen.com/books/eco-friendly-textile-dyeing-andfinishing/textile-dyes-dyeing-process-andenvironmental-impact. Accessed Mar 2020

Cinkotai FF, Emo P, Gibbs AC, Caillard JF, Jouany JM (1988) Low prevalence of byssinotic symptoms in 12 flax scutching mills in Normandy, France. Occup Environ Med 45(5):325-328

Dhirhi N, Shukla R, Patel NB, Sahu H, Mehta N (2015) Extraction method of flax fibre and its uses. Plant Archive 15(2):711-716

Elwood PC, Pemberton J, Merrett JD, Carey GCR, McAulay IR (1965) Byssinosis and other respiratory symptoms in flax workers in Northern Ireland. Occup Environ Med J 22(1):27-37

Friend MA, Kohn JP (2018) Ergonomic and safety management. Fundamentals of occupational safety and health. 7th edn. Rowman \& Littlefield, New York, pp 134-176

Goyal A, Sharma V, Upadhyay N, Gill S, Sihag M (2014) Flax and flaxseed oil: an ancient medicine \& modern functional food. J Food Sci Technol 51(9):1633-1653

Hinson AV, Schlünssen V, Agodokpessi G, Sigsgaards T, Fayomi B (2014) The prevalence of byssinosis among cotton workers in the north of Benin. Int J Occup Environ Med 5(4):448-194

Hinson AV, Lokossou VK, Schlünssen V, Agodokpessi G, Sigsgaard T, Fayomi B (2016) Cotton dust exposure and respiratory disorders among textile workers at a textile company in the southern part of Benin. Int J Environ Res Public Health 13(9):895

Jacobsen M, Rossiter CE, Wagner GR (1994) The ILO International Classification of Radiographs of Pneumoconiosis since 1980. The Ann Occup Hyg 38:777-782

Jafari MJ, Rahimi A, Omidi L, Behzadi MH, Rajabi MH (2015) Occupational exposure and health impairments of formaldehyde on employees of a wood industry. Health Promot Perspect 5(4): 296-303

Khan S, Malik A (2014) Environmental and health effects of textile industry wastewater. In: Environmental deterioration and human health. Springer, Dordrecht, pp 55-71

Khan AJ, Nanchal R (2007) Cotton dust lung diseases. Curr Opin Pulm Med 13(2):137-141

Kim KH, Jahan SA, Lee JT (2011) Exposure to formaldehyde and its potential human health hazards. J Environ Sci Health C 29(4):277299

Kobayashi H, Kanoh S, Motoyoshi K, Aida S (2004) Diffuse lung disease caused by cotton fibre inhalation but distinct from byssinosis. Thorax. 59(12):1095-1097

Mahmoud MT, Abd El-Megeed HS, Alaa El-Din SM, Ibrahim FH (2004) A study of occupational health hazards among assiut spinning factory workers. Ass Univ Bull Environ Res 7(1):63-74

Malik N, Maan AA, Pasha TS, Akhtar S, Ali T (2010) Role of hazard control measures in occupational health and safety in the textile industry of Pakistan. Pak J Agric Sci 47(1):72-76

McGwin G Jr, Lienert J, Kennedy JI Jr (2010) Formaldehyde exposure and asthma in children: a systematic review. Environ Health Perspect 118(3):313-317 
Morgan WK, Vesterlund J, Burrell R, Gee JB, Willoughby WF (1982) Byssinosis: some unanswered questions. Am Rev Respir Dis 126(2):354-357

Noweir MH, El-Sadik YM, El-Dakhakhny AA, Osman HA (1975) Dust exposure in manual flax processing in Egypt. Occup Environ Med 32(2):147-154

Noweir MH, Noweir KH, Myo Tint U, Win Z, Myint H (1990) A comparative environmental and medical study of dust exposure in jute and cotton mills in Burma. J Egypt Public Health Assoc 65(3-4): 349-375

Oldenburg M, Latza U, Baur X (2007) Exposure-response relationship between endotoxin exposure and lung function impairment in cotton textile workers. Int Arch Occup Environ Health 80:388-395

Parikh JR (1992) Byssinosis in developing countries. Br J Ind Med 49(4): 217-219

Parimalam P, Kamalamma N, Ganguli AK (2006) Ergonomic interventions to improve work environment in garment manufacturing units. Indian J Occup Environ Med 10(2):74

Rantanen J, Lehtinen S, Lavicoli S (2013) Occupational health services in selected International Commission on Occupational Health (ICOH) member countries. Scand J Work Environ Health 39:212-216

Saarinen L (1997) Cotton dust control. Afr Newsl Occup Health Safety 7: $12-13$
Schilling RSF, Vigliani EC, Lammers B, Valic F, Gilson J C. (1963) A report on a conference on byssinosis. In: Proceedings of the 14th International Congress on Occupational Health. Madrid, pp 137$145,5(2)$

Shephard RJ (1961) Ergonomics of the Respirator in Design and Use of Respirators. In: Proceedings of a Joint Meeting of the Ergonomics Research Society and the British Occupational Hygiene Society (Porton), Penguin, London

Singh SB, Gautam S, Bhatta N, Shrestha G, Gautam R, Poudel S (2019) Respiratory disorders among dust exposed workers. JNMA 57(215): 14-19

Smith DH, Lockhart W, Mair A, Wilson WA (1962) Flax workers' byssinosis in East Scotland. Scott Med J 7(5):201-211

WHO (1986) Early Detection of Occupational Disease. World Health Organization, Geneva, pp 30-32

WHO (1994) Global Strategy on Occupational Health for All. World Health Organization, Geneva

Zhang L, Steinmaus C, Eastmond DA, Xin XK, Smith MT (2009) Formaldehyde exposure and leukemia: a new meta-analysis and potential mechanisms. Mutat Res Rev Mutat Res 681(2-3):150-168

Publisher's note Springer Nature remains neutral with regard to jurisdictional claims in published maps and institutional affiliations. 